\title{
PENGARUH PENGEMBANGAN SELF-NANOEMULSIFYING DRUG DELIVERY SYSTEM TERHADAP DISOLUSI, BIOAVAILABILITAS, DAN AKTIVITAS AGEN ANTIHIPERLIPIDEMIA
}

\author{
'Sani Ega Priani*, 2Dyah Ayu Nurismawati, ${ }^{3}$ Fitrianti Darusman
}

1,2,3 Program Studi Farmasi, FMIPA, Universitas Islam Bandung

\section{Info Article}

Submitted :

23 November 2021

Revised :

22 Desember 2021

Accepted :

27 Januari 2022

Corresponding Author:

Sani Ega Priani

Email :

egapriani@gmail.com
Hiperlipidemia adalah suatu kondisi peningkatkan kadar lipid plasma yang dapat menjadi faktor resiko berbagai penyakit kardiovaskular. Diketahui beberapa agen antihiperlipidemia bersifat sukar larut dalam air sehingga dapat berpengaruh pada disolusi, bioavailabilitas, dan efek farmakologi yang dihasilkan. Selfnanoemulsifying Drug Delivery System (SNEDDS) merupakan salah satu sistem penghantaran obat yang diketahui mampu memperbaiki kelarutan zat sukar larut air. Kajian ini bertujuan untuk mengetahui pengaruh formulasi SNEDDS terhadap disolusi, bioavailabilitas, dan efektivitas dari agen antihiperlipidemia. Kajian berbasis systematic literature review dengan melakukan pengkajian artikel yang diperoleh dari database bereputasi yang memenuhi kriteria inklusi dan eksklusi yang telah ditetapkan. Hasil kajian menunjukkan formulasi SNEDDS terhadap agen antihiperlipidemia dapat menyebabkan peningkatan \% disolusi zat sukar larut air hingga mencapai $>80 \%$. Formulasi SNEDDS mampu meningkatkan bioavailabilitas zat, yang ditandai dengan peningkatan signifikan dari nilai Cmax dan AUC (area under curve) dibandingkan dengan bentuk murni dan suspensi. Formulasi SNEDDS juga mampu meningkatkan efektivitas antihiperlipidemia, yang ditandai dengan penurunan kadar kolesterol total, trigliserida, dan LDL yang lebih baik dibandingkan dengan zat murni dan sediaan di pasaran. Dari hasil kajian dapat disimpulkan bahwa pengembangan sediaan SNEDDS potensial untuk meningkatkan disolusi, bioavaibilitas, dan efektivitas terapi dari agen antihiperlipidemia.

Kata kunci: SNEDDS, hiperlipidemia, systematic literature review
Access this article

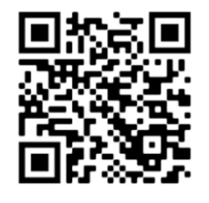

SCAN ME
ABSTRACT

Hyperlipidemia is a condition that increases plasma lipid levels, which can be a risk factor for various cardiovascular diseases. It is known that some antihyperlipidemic agents have low solubility in water, so that it has an impact on low dissolution, bioavailability, and the resulting pharmacological effects. Self-nano emulsifying Drug Delivery System (SNEDDS) is a drug delivery system that can improve the solubility of poorly water-soluble drugs. This study 
aims to determine the effect of the SNEDDS formulation on the dissolution, bioavailability, and effectiveness of antihyperlipidemic agents. A study based on a systematic literature review using articles obtained from reputable databases that meet the inclusion and exclusion criteria. The study results showed that the SNEDDS formulation for antihyperlipidemic agents could increase the \% dissolution of water-soluble substances up to $>80 \%$. The SNEDDS formulation increased the bioavailability of the substance, which was indicated by higher Cmax and AUC values compared to pure drug and suspension. The SNEDDS formulation can also increase the effectiveness of antihyperlipidemic agents, characterized by a better reduction in total cholesterol, triglyceride, and LDL levels than pure drug and market products. From the study results, it can be concluded that the development of SNEDDS preparations has the potential to increase the dissolution, bioavailability, and therapeutic effectiveness of antihyperlipidemic agents.

Keywords: SNEDDS, hyperlipidemic, systematic literature review

\section{PENDAHULUAN}

Menurut data WHO, Cardiovascular diseases (CVDs) atau penyakit kardiovaskular adalah penyebab kematian pertama di Dunia (Mc Namara et al., 2019). Salah satu faktor resiko terjadinya penyakit kardiovasular adalah kondisi hiperlipidemia. Seseorang yang mengalami kondisi hiperlipidemia, memiliki resiko dua kali lipat lebih tinggi untuk menderita penyakit kardiovaskular (Karr, 2017). Hiperlipidemia adalah kondisi kesehatan dimana terjadi peningkatan lipid plasma dan lipoprotein (Ezeh \& Ezeudemba, 2021). Hiperlipidemia ditandai dengan peningkatan satu atau lebih dari lipid plasma seperti trigliserida, kolesterol, kolesterol ester, fosfolipid atau terjadinya peningkatan lipoprotein sepeti VLDL (very low-density lipoprotein) dan LDL (low-density lipoprotein) disertai dengan penurunan kadar HDL (high-density lipoprotein) (Shattat, 2014). Kondisi hiperlipidemia harus diatasi secara tepat karena kondisi tersebut dapat menyebabkan tingginya resiko terkena jantung koroner (PJK), stroke, aterosklerosis, dan pankreatitis. (Harikumar et al., 2013; Su et al., 2021).

Terapi hiperlipidemia bisa dilakukan dengan pendekatan non farmakologi dan farmakologi. Terapi non farmakologi umum dilakukan dengan perubahan pola hidup terutama dengan modifikasi pola makan (Onwe et al., 2015). Sedangkan terapi farmakologi dilakukan dengan mengkonsumsi obat-obat antihiperlipidemia atau lipid lowering drugs (Ruscica et al., 2021). Pengobatan menggunakan agen antihiperlipidemia umum dilakukan dengan rute oral. Beberapa kelompok agen hiperlipidemia ini memiliki hambatan pada pemberian oral, berkaitan dengan sifat fisikokimianya. Agen antihiperlipidemia seperti simvastatin (Jiang et al., 2012), rosuvastatin calsium (Butt et al., 2019), atorvastatin (Prabhu \& Patravale, 2016), gemfibrozil (Reddy et al., 2011) termasuk ke dalam kelompok BCS (biopharmaceutical classification system) kelas II dengan kelarutan yang rendah dalam air dan permeabilitas yang baik (Van Den Abeele et al., 2016). Beberapa modifikasi formulasi banyak dilakukan 
untuk memperbaiki kelarutan dan bioavaibilitas dari senyawa-senyawa tersebut salah satunya dengan mengembangkan bentuk SNEDDS (selfnanoemulsifying drug delivery system) (Elgart et al., 2013).

SNEDDS adalah campuran isotropik antara minyak, surfaktan, dan kosurfaktan yang dapat membentuk nanoemulsi secara spontan ketika kontak dengan cairan saluran cerna yang disertai agitasi ringan (Nasr et al., 2016). SNEDDS mampu membentuk sistem nanoemulsi setelah didispersikan dalam air dengan ukuran globul <100 nm (Akiladevi et al., 2020). Formulasi SNEDDS diketahui mampu meningkatkan laju disolusi dari zat aktif yang diberikan secara oral salah satunya akibat peningkatan area antarmuka minyak dan air sehingga meningkatkan kelarutan dan bioavailabilitasnya (Savale, 2015).

Berdasarkan paparan di atas maka, tujuan dari kajian ini adalah melakukan review sistematis untuk mengetahui pengaruh formulasi SNEDDS terhadap disolusi, bioavailabilitas, dan efektivitas dari senyawa antihiperlipidemia oral. Pada kajian ini juga agak dibahas aspek formulasi untuk pengembangan SNEDDS mengandung agen antihiperlipidemia. Dari hasil kajian ini diharapkan bisa diketahui efek positif dari pengembangan bentuk sediaan SNEDDS untuk penghantaran oral zat aktif sukar larut lair baik yang termasuk agen antihiperlipidemia ataupun agen lainnya.

\section{METODE PENELITIAN}

Penelitian ini menggunakan metode systematic literatur review (SLR) yang merujuk PRISMA framework yakni identification, eligibility, screening, dan included. Proses pencarian artikel dilakukan melalui laman Science Direct (Elsevier), Taylor and Francis, dan Pubmed. Proses pencarian artikel menggunakan key words atau kata kunci, yakni self nanoemulsifying, SNEDDS, dan hyperlipidemia. Setelah diperoleh artikel yang berkaitan dengan topik penelitian, maka tahap selanjutnya dilakukan seleksi artikel berdasarkan kesesuaiannya dengan kriteria inklusi dan eksklusi yang telah dirancang sebelumnya. Sebagai kriteria inklusi adalah artikel penelitian mengenai SNEDDS mengandung agen antihiperlipidemia. Sedangkan sebagai kriteria eksklusi adalah artikel yang terbit diluar rentang tahun 2011-2021, artikel review, dan artikel SNEDDS tanpa uji disolusi/bioavailabilitas/efek

antihiperlipidemia. Terhadap artikel yang memenuhi kriteria inklusi dan eksklusi dilakukan ekstraksi data yang berkaitan dengan formulasi, karakteristik, hasil uji disolusi, bioavailabilitas, dan efek antihiperlipidemia (Priani et al., 2021). Hasil pencarian artikel menggunakan kata kunci tersebut mendapatkan 34 artikel dari laman Science direct, 27 artikel dari lama taylor dan francis dan 11 artikel di laman pubmed. Hasil seleksi menggunakan kriteria inklusi dan eksklusi diperoleh 12 artikel untuk selanjutnya dilakukan ekstraksi data dan analisis.

\section{HASIL DAN PEMBAHASAN}

Berdasarkan hasil kajian yang telah dilakukan diketahui sudah cukup banyak dikembangkan sistem SNEDDS untuk penghantaran oral agen antihiperlipidemia. SNEDDS sudah diaplikasikan terhadap simvastatin, 
atorvastatin, rosuvastatin, ezetimid,

gemfibrozil, dan perialdehid (Tabel 1).

Tabel 1. Formulasi dan karakterisasi SNEDDS agen antihiperlipidemia

\begin{tabular}{|c|c|c|c|}
\hline Nama zat aktif & Formulasi & Karakteristik & Pustaka \\
\hline \multirow[t]{2}{*}{ Atorvastatin } & $\begin{array}{l}\text { M: Asam oleat } \\
\text { S: Tween } 80 \\
\text { Ko-S: Propilenglikol }\end{array}$ & $\begin{array}{l}\text { UG : } 73,5 \mathrm{~nm} \\
\mathrm{PZ}:-24,1 \mathrm{mV}\end{array}$ & $\begin{array}{l}\text { (Hashem et al., } \\
\text { 2015) }\end{array}$ \\
\hline & $\begin{array}{l}\text { M : Minyak lemon } \\
\text { S : Cremophor EL \&Tween } \\
80 \\
\text { Ko-S : Transcutol }{ }^{\otimes} \mathrm{HP}\end{array}$ & $\begin{array}{l}\text { UG : } 5,66 \mathrm{~nm} \\
\text { PZ: }-19,52 \mathrm{mV} \text {, } \\
\text { WE : } 14 \text { detik }\end{array}$ & (Kassem et al., 2017) \\
\hline Ezetimib & $\begin{array}{l}\text { M: Maisine 35-1 } \\
\text { S: Labrasol \& tween } 80\end{array}$ & $\begin{array}{l}\text { UG: } 65,88 \mathrm{~nm} \\
\text { PZ: }-34,98 \mathrm{mV} \\
\text { WE: } 10.20 \text { detik }\end{array}$ & $\begin{array}{l}\text { (Bandyopadhyay et } \\
\text { al., 2012) }\end{array}$ \\
\hline Gemfibrozil & $\begin{array}{l}\text { M: Lemon essential oil } \\
\text { S: Cremophor EL } \\
\text { Ko-S: Capmul MCM-C8 }\end{array}$ & $\begin{array}{l}\text { UG: } 56,5 \mathrm{~nm} \\
\text { PDI: 0,26 }\end{array}$ & (Villar et al., 2012) \\
\hline Perillaldehyde & $\begin{array}{l}\text { M: Isopropyl myristate, } \\
\text { S: Cremophor EL, } \\
\text { Ko-S: PEG } 200\end{array}$ & $\begin{array}{l}\text { UG: } 32,8 \mathrm{~nm} \\
\text { PDI: } 0,27 \\
\text { PZ: }-10,14 \mathrm{mV}\end{array}$ & $\begin{array}{l}\text { (Omari-Siaw et al., } \\
\text { 2016) }\end{array}$ \\
\hline \multirow[t]{4}{*}{ Rosuvastatin } & $\begin{array}{l}\text { M :Capmul MCM EP } \\
\text { S: Tween } 20 \\
\text { Ko-S:Transcutol }\end{array}$ & $\begin{array}{l}\text { UG : } 14,69 \mathrm{~nm} \\
\text { PDI : } 0,5 \\
\text { WE : } 15 \text { detik }\end{array}$ & (Verma et al., 2021) \\
\hline & $\begin{array}{l}\text { M : olive oil dan garlic oil } \\
\text { S : Tween } 80 \\
\text { Ko-S : PEG } 400\end{array}$ & $\begin{array}{l}\text { UG : } 68 \pm 4,11 \mathrm{~nm} \\
\text { PDI : } 0,20 \pm 0.02 \\
P Z:+23,43 \pm 2,58 \mathrm{mV}\end{array}$ & (Abo Enin, 2015) \\
\hline & $\begin{array}{l}\text { M: Perilla frutescens oil } \\
\text { S: Cremophor EL } \\
\text { Ko-S: Propilen glikol } \\
\text { monolaurat }\end{array}$ & $\begin{array}{l}\text { UG: } 17,9 \mathrm{~nm} \\
\text { PZ: } 21 \mathrm{mV} \\
\text { WE: } 120 \text { detik }\end{array}$ & (Tripathi et al., 2018) \\
\hline & $\begin{array}{l}\text { M: Peceol } \\
\text { S: Tween } 80 \\
\text { Ko-S:Transcutol HP }\end{array}$ & $\begin{array}{l}\text { UG: } 36,6 \mathrm{~nm} \\
\text { PZ: }-11,2 \mathrm{mV} \\
\text { WE: } 131 \text { detik }\end{array}$ & (Beg et al., 2017) \\
\hline Simvastatin & $\begin{array}{l}\text { M: Labrafil } 1944 \text { CS } \\
\text { S: Tween } 80 \\
\text { Ko-S : Etanol }\end{array}$ & $\begin{array}{l}\text { UG : } 40,69 \mathrm{~nm} \\
\text { PDI : 0,257 } \\
\text { PZ : }-30,25 \mathrm{mV}\end{array}$ & (Sharma et al., 2018) \\
\hline $\begin{array}{l}\text { Kombinasi } \\
\text { atorvastatin } \\
\text { dan ezetimib }\end{array}$ & $\begin{array}{l}\text { M : Capryol } 90 \\
\text { S : Tween } 80+\text { Cremophor } \\
\text { RH } 40 \\
\text { Ko-S: Transcutol HP }\end{array}$ & $\begin{array}{l}\text { UG : } 101,3 \pm 047 \mathrm{~nm} \\
\text { PDI : } 0,24 \\
\text { PZ : }-23 \mathrm{mV} \\
\text { WE : }<60 \text { detik }\end{array}$ & $\begin{array}{l}\text { (Gardouh et al., } \\
\text { 2020) }\end{array}$ \\
\hline
\end{tabular}

Keterangan : M (minyak), S (surfaktan), Ko-S (kosurfaktan), UG (rata rata ukuran globul), PDI (poli dispersity index), PZ (potensial zeta), WE (waktu emulsifikasi)

Semua zat aktif tersebut memiliki kelarutan yang rendah dalam air, dan hal tersebut yang selanjutnya menjadi dasar pengembangannya dalam bentuk sediaan SNEDDS. Sediaan diformulasikan menggunakan minyak, surfaktan, dan kosurfaktan. Pemilihan jenis minyak didasarkan pada kemampuannya untuk melarutkan zat aktif dengan baik (Khattab et al., 2017). Minyak yang dapat melarutkan zat aktif dengan baik, akan meningkatkan kapasitas sediaan untuk 
melarutkan zat aktif, terutama untuk zat aktif yang bersifat sukar larut dalam air. Selain itu pemilihan minyak juga dapat didasarkan pada adanya aktivitas minyak sebagai antihiperlipidemia sehingga dapat menunjang efektivitas dari sediaan seperti penggunaan garlic oil dan perilla frutescens oil pada SNEDDS rosuvasatin (Tripathi et al., 2018).

Eksipien lainnya yang ditambahkan adalah surfaktan. Surfaktan ditambahkan untuk membentuk lapisan pada permukaan globul minyak ketika nantinya sediaan SNEDDS terdispersi dalam air. Selain itu surfaktan dapat menurunkan nilai tegangan permukaan sehingga menurunkan nilai energi bebas dan meningkatkan stabilitas. Surfaktan yang banyak digunakan pada pengembangan sediaan SNEDDS agen antihiperlipidemia adalah tween 80/tween 20 dan cremophor EL/cremophor RH 40. Seluruhnya merupakan jenis surfaktan nonionik yang banyak digunakan untuk formulasi sediaan SNEDDS karena toksisitasnya yang lebih rendah dibanding surfaktan kationik dan anionik (Mustapha \& Bawa-Allah, 2020). Tween dan cremophor juga memiliki nilai HLB>12 sehingga sesuai digunakan untuk sediaan SNEDDS yang dirancang untuk dengan cepat terdispersi dalam air membentuk nanoemulsi minyak dalam air di saluran cerna. Selain penambahan surfaktan, umum dilakukan penambahan kosurfaktan. Kosurfaktan ditambahkan untuk membantu membentuk lapisan antar muka yang lebih rapat dan fleksibel dan juga lebih menurunkan nilai tegangan permukaan, dan menstabilkan sistem (Krstić et al., 2018). Kosurfaktan yang paling banyak digunakan pada formulasi SNEDDS merujuk pada tabel 1 adalah propilenglikol, transcutol, dan polietilenglikol.

Dari hasil karakterisasi sediaan diketahui sediaan SNEDDS yang dihasilkan memiliki karakteristik yang baik dan mampu membentuk nanoemulsi secara spontan ketika terdispersi dalam air. Nilai diameter globul berada pada rentang 5-73 $\mathrm{nm}$ dengan nilai $\mathrm{PDI} \leq 0,5$, yang memenuhi persyaratan globul untuk SNEDDS yakni $<100 \mathrm{~nm}$ (Vu et al., 2020). Beberapa jurnal juga melakukan analisis potensial zeta untuk sediaan SNEDDS, untuk memprediksi stabilitas. Idealnya nilai potensial zeta adalah $> \pm 30 \mathrm{mV}$. Namun diketahui bahwa pengukuran potensial zeta tidak terlalu relevan dilakukan untuk menilai stabilitas dari sediaan SNEDDS, mengingat SNEDDS merupakan sistem prekonsentrat yang baru akan membentuk sistem dispersi nanoemulsi di saluran cerna (Krstić et al., 2018). Parameter lain yang dilihat adalah waktu emulsifikasi yang berguna untuk memprediksi seberapa cepat sediaan SNEDDS akan membentuk sistem nanoemulsi ketika kontak dengan air. Hasilnya menunjukkan waktu yang relatif singkat yakni pada rentang 14-131 detik.

\subsection{Pengaruh formulasi SNEDDS terhadap disolusi zat aktif}

Pada Tabel 2, diperlihatkan pengaruh formulasi SNEDDS terhadap disolusi dari agen hiperlipidemia oral. 
Tabel 2. Pengaruh formulasi SNEDDS terhadap disolusi

\begin{tabular}{|c|c|c|c|}
\hline \multirow{2}{*}{ Zat aktif } & \multicolumn{2}{|l|}{ Disolusi } & \multirow{2}{*}{ Pustaka } \\
\hline & Zat murni/suspensi & SNEDDS & \\
\hline \multirow[b]{2}{*}{ Atorvastatin } & $53,3 \%$ & $86,53 \%$ & (Hashem et al., 2015) \\
\hline & $\begin{array}{l}\text { pH } 1,2: 21,34 \pm 4,61 \% \\
\text { pH } 6,8: 62,66 \pm 2,14 \%\end{array}$ & $\begin{array}{l}\mathrm{pH} \quad 1,2: 97,12 \\
\pm 2,63 \% \\
\mathrm{pH} 6,8: \\
\pm 2,52 \%\end{array}$ & (Kassem et al., 2017) \\
\hline Ezetimib & $27,36 \%$. & $>90 \%$ & (Bandyopadhyay et al., 2012) \\
\hline Gemfibrozil & $30 \%$ & $90 \%$ & (Villar et al., 2012) \\
\hline Perillaldehyde & $35 \%$ & $95 \%$ & (Omari-Siaw et al., 2016) \\
\hline \multirow{4}{*}{ Rosuvastatin } & $\pm 70 \%$ & $98,32 \pm 0,05 \%$ & (Verma et al., 2021) \\
\hline & $<30 \%$ & $>85 \%$ & (Abo Enin, 2015) \\
\hline & $38 \%$ & $98 \%$ & (Tripathi et al., 2018) \\
\hline & - & $>80 \%$ & (Beg et al., 2017) \\
\hline Simvastatin & $<45 \%$ & $>90 \%$ & (Sharma et al., 2018) \\
\hline $\begin{array}{l}\text { Kombinasi } \\
\text { atorvastatin dan } \\
\text { ezetimib }\end{array}$ & $<6 \%$ & $>99 \%$ & (Gardouh et al., 2020) \\
\hline
\end{tabular}

Pada tabel tersebut terlihat bagaimana pengaruh pengembangan sediaan SNEDDS terhadap disolusi zat aktif dibandingkan dengan bentuk murninya (suspensi). Disolusi adalah proses melarutnya zat aktif dalam medium pembawanya. Profil disolusi dari formula SNEDDS diuji secara in vitro menggunakan apparatus dan media disolusi yang sesuai. Berdasarkan pada tabel 2, dapat terlihat bahwa formulasi SNEDDS mampu meningkatkan disolusi dari zat aktif yang memiliki karakteristik alami sukar larut dalam air. Hal tersebut dapat terlihat dari peningkatan persen zat yang terdisolusi pada formula SNEDDS yang berbeda bermakna dengan bentuk murninya. Setelah diformulasi menjadi sediaan SNEDDS semua agen antihiperlipidemia yang sukar larut air, mampu terdisolusi $>80 \%$. Peningkatan $\%$ disolusi zat aktif melalui sistem penghantaran SNEDDS dapat terjadi karena zat aktif terlarut dalam globul minyak berukuran nano yang terbungkus oleh lapisan surfaktan dan kosurfaktan yang memungkin untuk terdispersi dengan mudah dalam air. Keberadaan surfaktan dan kosurfaktan juga bisa mempermudah proses pelarutan zat aktif. (Abo Enin, 2015).

\subsection{Pengaruh formulasi SNEDDS terhadap bioavailabilitas zat aktif \\ Selain mengkaji pengaruh formulasi SNEDDS terhadap disolusi juga dilakukan kajian pengaruhnya terhadap nilai bioavailabilitas atau ketersediaan hayati yang ditampilkan pada Tabel 3.}


Tabel 3. Pengaruh formulasi SNEDDS terhadap bioavailabilitas

\begin{tabular}{|c|c|c|c|}
\hline \multirow{2}{*}{ Zat Aktif } & \multicolumn{2}{|l|}{ Bioavailabilitas } & \multirow{2}{*}{ Pustaka } \\
\hline & Zat murni/suspensi & SNEDDS & \\
\hline \multirow[t]{3}{*}{ Atorvastatin } & $\begin{array}{l}\text { Cmax : } 1,793 \mu \mathrm{g} / \mathrm{mL} \\
\text { AUC: } 31,304 \mu \mathrm{g} . \mathrm{jam} / \mathrm{mL}\end{array}$ & $\begin{array}{l}\text { Cmax : } 8,099 \mu \mathrm{g} / \mathrm{mL} \\
\text { AUC : } 84,612 \mu \mathrm{g} . j \mathrm{jm} / \mathrm{mL}\end{array}$ & $\begin{array}{l}\text { (Hashem et } \\
\text { al., 2015) }\end{array}$ \\
\hline & Cmax : $10.13 \pm 0.89 \mu \mathrm{g} / \mathrm{r}$ & $\mathrm{Cmax}: 17.34 \pm 1.06 \mu \mathrm{g} / \mathrm{ml}$ & (Kassem et \\
\hline & $\mathrm{am} / \mathrm{mL}$ & $\begin{array}{l}\text { AUC : } 371.32 \pm 35.92 \\
\mu \mathrm{g} . \mathrm{jam} / \mathrm{mL}\end{array}$ & \\
\hline \multirow[t]{2}{*}{ Perillaldehyde } & $\mathrm{Cma}$ & Cmax : $1,736 \mu \mathrm{g} / \mathrm{mL}$ & \\
\hline & AUC & AUC : $7,487 \mu$ & $\begin{array}{l}\text { Siaw et al., } \\
\text { 2016) }\end{array}$ \\
\hline \multirow[t]{2}{*}{ Rosuvastatin } & $\begin{array}{l}\text { Cmax : } 234,80 \mu \mathrm{g} / \mathrm{mL} \\
\text { AUC : } 2364,25 \mu \mathrm{g} . j \mathrm{am} / \mathrm{mL}\end{array}$ & $\begin{array}{l}\text { Cmax : 606,13 } \mu \mathrm{g} / \mathrm{mL} \\
\text { AUC : } 6195,16 \mu \mathrm{g} . j \mathrm{am} / \mathrm{mL}\end{array}$ & $\begin{array}{l}\text { (Tripathi et } \\
\text { al., 2018) }\end{array}$ \\
\hline & $\begin{array}{l}\text { Nilai Cmax SNEDDS meningkat } \\
\text { SNEDDS meningkat } 1,8 \text { kali lipat }\end{array}$ & 5,7 kali lipat dan nilai $A U C$ & $\begin{array}{l}\text { (Beg et al., } \\
2017)\end{array}$ \\
\hline Simv & \multicolumn{2}{|c|}{$\begin{array}{l}\text { Nilai AUC dari sediaan SNEDDS yang telah disolidifikasi } \\
\text { meningkat } 2,10 \text { kali dibanding dengan bentuk tablett di pasaran } \\
\text { sedangkan nilai bioavailibilas naik } 3,28 \text { kali }\end{array}$} & $\begin{array}{l}\text { (Sharma et al., } \\
\text { 2018) }\end{array}$ \\
\hline \multirow{2}{*}{$\begin{array}{l}\text { Kombinasi } \\
\text { atorvastatin } \\
\text { dan ezetimib }\end{array}$} & $\begin{array}{l}\text { Cmax ator: } 8,19 \pm 0,11 \mu \mathrm{g} / \mathrm{ml} \\
\text { AUC ator: } 59,04 \pm 1,07 \mu \mathrm{g} \cdot \mathrm{hr} / \mathrm{ml}\end{array}$ & $\begin{array}{l}\text { Cmax ator: } 18,20 \pm 0.05 \mu \mathrm{g} / \mathrm{ml} \\
\text { AUC ator: } 209,5 \pm 2,3 \mu \mathrm{g} . \mathrm{hr} / \mathrm{ml}\end{array}$ & $\begin{array}{l}\text { (Gardouh et } \\
\text { al., 2020) }\end{array}$ \\
\hline & $\begin{array}{l}\text { Cmax ezet: } 7,75 \pm 0,12 \mu \mathrm{g} / \mathrm{ml} \\
\text { AUC ezet: } 48,73 \pm 1,95 \mu \mathrm{g} / \mathrm{ml}\end{array}$ & $\begin{array}{l}\text { Cmax ezet: } 18,08 \quad \pm 0,13 \\
\mu \mathrm{g} / \mathrm{ml} \\
\text { AUC ezet: } 183,8 \pm 2,7 \mu \mathrm{g} \cdot \mathrm{hr} / \mathrm{ml}\end{array}$ & \\
\hline
\end{tabular}

Bioavailabilitas atau ketersediaan hayati menunjukkan fraksi obat yang berhasil masuk ke sirkulasi sistemik setelah pemberian obat dalam bentuk sediaan tertentu (Allam et al., 2011). Jumlah obat yang sampai ke darah bisa dilihat dari parameter nilai Cmax (konsentrasi maksimal) dan AUC (area under curve) berdasarkan pengujian in vivo. Berdasarkan data yang ditampilkan pada tabel 3, terlihat bahwa formulasi SNEDDS mampu meningkatkan bioavailabilitas atau ketersediaan hayati dari agen hiperlipidemia yang ditandai dengan peningkatan nilai Cmax dan AUC dibandingkan dengan zat murni/suspensi. Peningkatan bioavailabilitas menunjukkan bahwa proses absorbsi zat aktif di saluran cerna terjadi lebih baik, yang menyebabkan zat aktif yang berhasil berpindah dari saluran cerna ke sirkulasi sistemik lebih banyak. Proses peningkatan absorbsi ini dapat terjadi karena dua faktor. Yang pertama karena kelarutan zat aktif yang semakin baik, yang dapat mempermudah proses absorpsinya. Faktor lainnya karena zat aktif yang terlarut dalam nanoglobul minyak memungkinkan untuk terjadinya absorbsi melalui mekanisme transselular/paraselular atau melalui jalur limfatik. (Celik-Tekeli et al., 2021).

\subsection{Pengaruh formulasi SNEDDS terhadap efek antihiperlipidemia}

Salah satu tujuan dari modifikasi bentuk sediaan adalah meningkatan efektivitas terapi. Konsumsi agen hiperlipidemia ditujukan untuk menurunkan kadar lipid plasma terutama pada pasien yang mengalami kondisi hiperlipidemia. Pada tabel 4 dipaparkan bagaimana pengaruh bentuk sediaan SNEDDS terhadap efektivitas kerja dari agen antihiperlipidemia. 
Tabel 4. Pengaruh formulasi SNEDDS terhadap efek antihiperlipidemia

\begin{tabular}{|c|c|c|}
\hline Nama zat aktif & Efek antihiperlipidemia & Pustaka \\
\hline Atorvastatin & $\begin{array}{l}\text { Pemberian SNEDDS atorvastatin secara signifikan } \\
\text { menurunkan kadar kolesterol total lebih baik dibandingkan } \\
\text { dengan bentuk sediaan suspensi }\end{array}$ & $\begin{array}{l}\text { (Kassem et al., } \\
\text { 2017) }\end{array}$ \\
\hline Ezetmib & $\begin{array}{l}\text { Formulasi SNEDSS meningkatkan penurunan kadar } \\
\text { trigliserida dan LDL di bandingkan dengan pemberian } \\
\text { dalam bentuk suspensi } \\
\text { Suspensi : penurunan TG } 24,49 \% \text {; LDL } 23,85 \% \\
\text { SNEDDS: penurunan TG } 53,67 \% \text {; LDL : } 41,22 \%\end{array}$ & $\begin{array}{l}\text { (Bandyopadhyay } \\
\text { et al., 2012) }\end{array}$ \\
\hline Perillaldehyde & $\begin{array}{l}\text { Formulasi SNEDDS perillaldehyde memberikan efek } \\
\text { antihiperlipidemia yang relatif setara dengan sediaan } \\
\text { pasaran mengandung senyawa sintetik lovastatin } \\
\text { Lovastatin : Penurunan KT } 14,67 \% \text {; TG : } 36 \% \text {; LDL : } 11,52 \% \\
\text { SNEDDS : KT : Penurunan } 14,36 \% \text {; TG: } 37,14 \% \text {; LDL: } 10 \%\end{array}$ & $\begin{array}{l}\text { (Omari-Siaw et } \\
\text { al., 2016) }\end{array}$ \\
\hline Rosuv & $\begin{array}{l}\text { Formulasi SNEDDS menyebabkan penurunan kadar CT, TG, } \\
\text { LDL, dan VLDL yang lebih baik dan berbeda bermakna } \\
\text { dengan bentuk murninya dan bentuk tablet yang ada di } \\
\text { pasaran }\end{array}$ & $\begin{array}{l}\text { (Verma et al., } \\
2021)\end{array}$ \\
\hline
\end{tabular}

Formulasi SNEDDS menurunkan kadar kolesterol total dan (Ahsan \& Prasad trigliserida yang berbeda bermakna dengan bentuk sediaan Verma, 2017) suspensi

\begin{tabular}{|c|c|}
\hline $\begin{array}{l}\text { Formulasi SNEDDS memberikan penurunan kadar KT, TG, } \\
\text { dan LDL berturut-turut } 188 \pm 50,93,87,94 \pm 40,14,89,70 \pm \\
96,70 \mathrm{mg} / \mathrm{dL} \text {, yang berbeda bermakna dengan sediaan di } \\
\text { pasaran dan bentuk murninya (suspensi) }\end{array}$ & (Abo Enin, 2015) \\
\hline $\begin{array}{l}\text { Formulasi SNEDDS memberikan penurunan kadar } \\
\text { kolesterol total, trigliserida, dan LDL yang lebih baik dari zat } \\
\text { aktif murni (bentuk suspensi) } \\
\text { Suspensi : Penurunan KT : } 38,1 \% \text {; TG : } 15 \% \text {; LDL : } 62,5 \% \\
\text { SNEDDS : Penurunan KT : } 50 \% \text {; TG : } 52,37 \% \text {; LDL } 81,35 \%\end{array}$ & $\begin{array}{l}\text { (Tripathi et al., } \\
\text { 2018) }\end{array}$ \\
\hline $\begin{array}{l}\text { Formulasi SNEDDS memberikan penurunan kadar } \\
\text { kolesterol total, trigliserida, dan LDL yang lebih baik dari } \\
\text { bentuk suspensi } \\
\text { Suspensi : Penurunan KT : } 41 \% \text {; TG 18\%; LDL } 22 \% \\
\text { SNEDDS : Penurunan KT 52\%; TG 45\%; LDL 35\% }\end{array}$ & Beg et al., 2017) \\
\hline
\end{tabular}

Hasil kajian menunjukkan bahwa pengembangan SNEDDS mampu menyebabkan penurunan kadar lipid plama yakni kolesterol total, trigliserida, $L D L$, dan VLDL, dibandingkan dengan pemberian zat aktif murni ataupun sediaan di pasaran. Formulasi SNEDDS sebagai sistem penghantaran memberikan peningkatan solubilitas sehingga mudah terdisolusi dan terabsorpsi. Obat yang terabsorpsi dengan baik akan memberikan bioavailabilitas yang baik pula dalam tubuh. Akumulasi obat dalam darah tentunya akan meningkatkan efek farmakologi yang dihasilkan dari suatu obat yang ditujukan untuk menghasilkan efek sistemik. 


\section{KESIMPULAN}

Hasil kajian menunjukkan formulasi SNEDDS terhadap agen antihiperlipidemia dapat menyebabkan peningkatan \% disolusi zat sukar larut air hingga mencapai $>80 \%$. Formulasi SNEDDS mampu meningkatkan bioavailabilitas zat, yang ditandai dengan peningkatan signifikan dari nilai Cmax dan AUC (area under curve) dibandingkan dengan bentuk murni/suspensi. Formulasi SNEDDS juga mampu meningkatkan efektivitas antihiperlipidemia, yang ditandai dengan penurunan kadar kolesterol total, trigliserida, dan LDL yang lebih baik dibandingkan dengan zat murni/sediaan di pasaran.

\section{UCAPAN TERIMA KASIH}

Ucapan terima kasih kami sampaikan kepada LPPM Unisba yang telah membantu pendanaan kegiatan kajian ini.

\section{DAFTAR PUSTAKA}

Abo Enin, H. A. (2015). Self-nanoemulsifying drug-delivery system for improved oral bioavailability of rosuvastatin using natural oil antihyperlipdemic. Drug Development and Industrial Pharmacy, 41(7). https://doi.org/10.3109/03639045.2014.98 3113

Ahsan, M. N., \& Prasad Verma, P. R. (2017). Solidified self nano-emulsifying drug delivery system of rosuvastatin calcium to treat diet-induced hyperlipidemia in rat: In vitro and in vivo evaluations. Therapeutic Delivery, 8(3). https://doi.org/10.4155/tde2016-0071

Akiladevi, D., Prakash, H., Biju, G., \& Madumitha, N. (2020). Nano-novel approach: Self nano emulsifying drug delivery system (SNEDDS) - Review article. In Research Journal of Pharmacy and Technology (Vol. 13, Issue 2). https://doi.org/10.5958/0974360X.2020.00183.3

Allam, A. N., El gamal, S. S., \& Naggar, V. F. (2011). Bioavailability: A Pharmaceutical
Review Bioavailability. Novel Drug Deliv Tech, 1(1).

Bandyopadhyay, S., Katare, O. P., \& Singh, B. (2012). Optimized self nano-emulsifying systems of ezetimibe with enhanced bioavailability potential using long chain and medium chain triglycerides. Colloids and Surfaces B: Biointerfaces, 100. https://doi.org/10.1016/j.colsurfb.2012.05. 019

Beg, S., Katare, O. P., \& Singh, B. (2017). Formulation by design approach for development of ultrafine selfnanoemulsifying systems of rosuvastatin calcium containing long-chain lipophiles for hyperlipidemia management. Colloids and Surfaces B: Biointerfaces, 159. https://doi.org/10.1016/j.colsurfb.2017.08. 050

Butt, S., Hasan, S. M. F., Hassan, M. M., Alkharfy, K. M., \& Neau, S. H. (2019). Directly compressed rosuvastatin calcium tablets that offer hydrotropic and micellar solubilization for improved dissolution rate and extent of drug release. Saudi Pharmaceutical Journal, 27(5). https://doi.org/10.1016/j.jsps.2019.03.002

Celik-Tekeli, M., Celebi, N., Tekeli, M. Y., \& Aktas, Y. (2021). Evaluation of the hypoglycemic effect of exendin-4's new oral selfnanoemulsifying system in rats. European Journal of Pharmaceutical Sciences, 158. https://doi.org/10.1016/j.ejps.2020.105644 Elgart, A., Cherniakov, I., Aldouby, Y., Domb, A. J., \& Hoffman, A. (2013). Improved oral bioavailability of BCS class 2 compounds by self nano-emulsifying drug delivery systems (SNEDDS): The underlying mechanisms for amiodarone and talinolol. Pharmaceutical Research, 30(12). https://doi.org/10.1007/s11095-013-1063$y$

Ezeh, K. J., \& Ezeudemba, O. (2021). Hyperlipidemia: A Review of the Novel Methods for the Management of Lipids. Cureus.

https://doi.org/10.7759/cureus.16412

Gardouh, A. R., Nasef, A. M., Mostafa, Y., \& Gad, S. (2020). Design and evaluation of combined atorvastatin and ezetimibe optimized self- nano emulsifying drug delivery system. Journal of Drug Delivery 
Science and Technology, 60. https://doi.org/10.1016/j.jddst.2020.10209 3

Harikumar, K., Althaf, S. A., Kishore Kumar, B., Ramunaik, M., \& Suvarna, C. (2013). A Review on Hyperlipidemic. Nternational Journal of Novel Trends in Pharmaceutical Sciences, 3(4).

Hashem, F. M., Al-Sawahli, M. M., Nasr, M., \& Ahmed, O. A. A. (2015). Custom fractional factorial designs to develop atorvastatin self-nanoemulsifying and nanosuspension delivery systems - Enhancement of oral bioavailability. Drug Design, Development and Therapy, 9. https://doi.org/10.2147/DDDT.S86126

Jiang, T., Han, N., Zhao, B., Xie, Y., \& Wang, S. (2012). Enhanced dissolution rate and oral bioavailability of simvastatin nanocrystal prepared by sonoprecipitation. Drug Development and Industrial Pharmacy, 38(10).

https://doi.org/10.3109/03639045.2011.64 5830

Karr, S. (2017). Epidemiology and management of hyperlipidemia. In The American journal of managed care (Vol. 23, Issue 9).

Kassem, A. M., Ibrahim, H. M., \& Samy, A. M. (2017). Development and optimisation of atorvastatin calcium loaded selfnanoemulsifying drug delivery system (SNEDDS) for enhancing oral bioavailability: in vitro and in vivo evaluation. Journal of Microencapsulation, 34(3). https://doi.org/10.1080/02652048.2017.13 28464

Khattab, A., Hassanin, L., \& Zaki, N. (2017). SelfNanoemulsifying Drug Delivery System of Coenzyme (Q10) with Improved Dissolution, Bioavailability, and Protective Efficiency on Liver Fibrosis. AAPS PharmSciTech, 18(5). https://doi.org/10.1208/s12249-016-0632$\mathrm{x}$

Krstić, M., Medarević, Đ., Đuriš, J., \& Ibrić, S. (2018). Self-nanoemulsifying drug delivery systems (SNEDDS) and selfmicroemulsifying drug delivery systems (SMEDDS) as lipid nanocarriers for improving dissolution rate and bioavailability of poorly soluble drugs. In
Lipid Nanocarriers for Drug Targeting. https://doi.org/10.1016/B978-0-12813687-4.00012-8

Mc Namara, K., Alzubaidi, H., \& Jackson, J. K. (2019). $<\mathrm{p}>$ Cardiovascular disease as a leading cause of death: how are pharmacists getting involved? $</ p>$. Integrated Pharmacy Research and Practice, Volume 8. https://doi.org/10.2147/iprp.s133088

Mustapha, D. S., \& Bawa-Allah, K. A. (2020). Differential toxicities of anionic and nonionic surfactants in fish. Environmental Science and Pollution Research, 27(14). https://doi.org/10.1007/s11356-02008212-6

Nasr, A., Gardouh, A., \& Ghorab, M. (2016). Novel solid self-nanoemulsifying drug delivery system (S-SNEDDS) for oral delivery of olmesartan medoxomil: Design, formulation, pharmacokinetic and bioavailability evaluation. Pharmaceutics, 8(3).

https://doi.org/10.3390/pharmaceutics803 0020

Omari-Siaw, E., Zhu, Y., Wang, H., Peng, W., Firempong, C. K., Wang, Y.W., Cao, X., Deng, W., Yu, J., \& Xu, X. (2016). Hypolipidemic potential of perillaldehyde-loaded selfnanoemulsifying delivery system in highfat diet induced hyperlipidemic mice: Formulation, in vitro and in vivo evaluation. European Journal of Pharmaceutical Sciences, 85. https://doi.org/10.1016/j.ejps.2016.02.003

Onwe, P., Folawiyo, M., Ogah, A., Umahi, G., Okorocha, A., \& Afoke, A. (2015). Hyperlipidemia: Etiology and Possible Control. IOSR Journal of Dental and Medical Sciences, 14(10).

Prabhu, P., \& Patravale, V. (2016). Dissolution enhancement of atorvastatin calcium by co-grinding technique. Drug Delivery and Translational Research, 6(4). https://doi.org/10.1007/s13346-015-0271$x$

Priani, S. E., Setianty, T. N., Aryani, R., Fitrianingsih, S. P., \& Syafnir, L. (2021). Development of Nanocapsules Containing Cytotoxic Agents- A Review. Jurnal Farmasi Galenika (Galenika Journal of Pharmacy) (eJournal),

$7(2)$. 
https://doi.org/10.22487/j24428744.2021.v 7.i2.15578

Reddy, K. V., Reddy, D. N., \& Reddy, K. H. (2011). Conseption and evaluation of Gemfibrozil as immediate drug delivery system. Journal of Chemical and Pharmaceutical Research, $3(2)$.

Ruscica, M., Ferri, N., Santos, R. D., Sirtori, C. R., \& Corsini, A. (2021). Lipid Lowering Drugs: Present Status and Future Developments. In Current Atherosclerosis Reports (Vol. 23, Issue 5). https://doi.org/10.1007/s11883021-00918-3

Savale, S. K. (2015). a Review - Self Nanoemulsifying Drug Delivery System (Snedds). International Journal of Research in Pharmaceutical and Nano Sciences.

Sharma, P., Singh, S. K., Pandey, N. K., Rajesh, S. Y., Bawa, P., Kumar, B., Gulati, M., Singh, S., Verma, S., Yadav, A. K., Wadhwa, S., Jain, S. K., Gowthamarajan, K., Malik, A. H., Gupta, S., \& Khursheed, R. (2018). Impact of solid carriers and spray drying on pre/postcompression properties, dissolution rate and bioavailability of solid selfnanoemulsifying drug delivery system loaded with simvastatin. Powder Technology, 338. https://doi.org/10.1016/j.powtec.2018.07.0 92

Shattat, G. F. (2014). A review article on hyperlipidemia: Types, treatments and new drug targets. In Biomedical and Pharmacology Journal (Vol. 7, Issue 2). https://doi.org/10.13005/bpj/504

Su, L., Mittal, R., Ramgobin, D., Jain, R., \& Jain, R. (2021). Current Management Guidelines on Hyperlipidemia: The Silent Killer. Journal of Lipids, 2021. https://doi.org/10.1155/2021/9883352

Tripathi, C. B., Gupta, N., Kumar, P., Singh, A. K., Raj, V., Parashar, P., Singh, M., Kanoujia, J.,
Arya, M., Saraf, S. A., \& Saha, S. (2018). w-3 Fatty Acid Synergized Novel Nanoemulsifying System for Rosuvastatin Delivery: In Vitro and In Vivo Evaluation. AAPS PharmSciTech, 19(3). https://doi.org/10.1208/s12249-017-09338

Van Den Abeele, J., Brouwers, J., Mattheus, R., Tack, J., \& Augustijns, P. (2016). Gastrointestinal Behavior of Weakly Acidic BCS Class II Drugs in Man - Case Study of Diclofenac Potassium. Journal of Pharmaceutical Sciences, 105(2). https://doi.org/10.1002/jps.24647

Verma, R., Kaushik, A., Almeer, R., Habibur Rahman, M., Abdel-Daim, M. M., \& Kaushik, D. (2021). Improved pharmacodynamic potential of rosuvastatin by selfnanoemulsifying drug delivery system: An in vitro and in vivo evaluation. International Journal of Nanomedicine, 16. https://doi.org/10.2147/IJN.S287665

Villar, A. M. S., Naveros, B. C., Campmany, A. C. C., Trenchs, M. A., Rocabert, C. B., \& Bellowa, L. H. (2012). Design and optimization of selfnanoemulsifying drug delivery systems (SNEDDS) for enhanced dissolution of gemfibrozil. International Journal of Pharmaceutics, $431(1-2)$. https://doi.org/10.1016/j.ijpharm.2012.04. 001

Vu, G. T. T., Phan, N. T., Nguyen, H. T., Nguyen, H. C., Hai Tran, Y. T., Pham, T. B., Nguyen, L. T., \& Nguyen, H. D. (2020). Application of the artificial neural network to optimize the formulation of self-nanoemulsifying drug delivery system containing rosuvastatin. Journal of Applied Pharmaceutical Science, 10(9).

https://doi.org/10.7324/JAPS.2020.10901

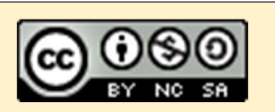

Copyright $\odot 2020$ The author(s). You are free to Share - copy and redistribute the material in any medium or format. Adapt - remix, transform, and build upon the material. Under the following terms: Attribution - You must give appropriate credit, provide a link to the license, and indicate if changes were made. You may do so in any reasonable manner, but not in any way that suggests the licensor endorses you or your use. NonCommercial - You may not use the material for commercial purposes. ShareAlike - If you remix, transform, or build upon the material, you must distribute your contributions under the same license as the original. No additional restrictions - You may not
apply legal terms or technological measures that legally restrict others from doing anything the license permits. 